\title{
A ontologia de Lukács e a restauração da crítica ontológica em Marx
}

\author{
Mario Duayer \\ Universidade do Estado do Rio de Janeiro (UERJ)

\section{María Fernanda Escurra} \\ Universidade do Estado do Rio de Janeiro (UERJ)
}

Andrea Vieira Siqueira

Universidade do Estado do Rio de Janeiro (UERJ)

\section{A ontologia de Lukács e a restauração da crítica ontológica em Marx}

Resumo: O presente artigo acentua a relevância da obra póstuma de Lukács, Ontologia do ser social, para a restituição da dimensão de crítica ontológica do pensamento marxiano. Considera especialmente o capítulo sobre o trabalho, onde o autor começa a delinear o ser social capturando suas categorias específicas. É no trabalho, como categoria mediadora por excelência, que o autor busca a gênese das categorias: finalidade, consciência, separação sujeito-objeto, ciência, alternativa, valor e liberdade. Nesse particular, focaliza algumas dessas categorias que não costumam receber muito destaque, inclusive em trabalhos dedicados à Ontologia.

Palavras-chave: Ontologia. Trabalho. Ser social. Crítica ontológica.

\section{The Ontology of Lukács and the Restoration of Ontological Criticism in Marx}

Abstract: This article emphasizes the relevance of Lukács' posthumous work Ontology of the Social Being for the restitution of the dimension of ontological criticism of Marxian thinking. It especially considers the chapter on labor, in which Lukács begins to delineate the social being and capture his specific categories. It is in labor, as a mediating category par excellence, that the author seeks the genesis of the categories: finality, awareness, separation of subject-object, science, alternative, value and liberty. The paper focuses on some of these categories that are not usually emphasized, including in works dedicated to Ontology.

Keywords: Ontology. Labor. Social being. Ontological criticism. 


\section{Introdução}

O presente artigo, ao sustentar a importância da Ontologia do ser social, obra da última fase da longa e profícua atividade intelectual de Georg Lukács, procura contemplar as questões: "fundação e origens do pensamento marxista e a explicação marxista de mundo"; "apropriação epistemológica e ontológica do marxismo no Serviço Social"; e "dilemas e desafios contemporâneos" para pensar as práticas possíveis para uma efetiva transformação do mundo. De fato, a obra de síntese de um autor, que já no final da década de 60 do século passado, a propósito da invasão da antiga Tchecoslováquia, em 1968, pelas tropas do Pacto de Varsóvia, declara a um ex-aluno que "parece que todo o experimento iniciado em 1917 fracassou e tudo tem de ser começado outra vez num outro lugar" (LUKÁCS, 1999, p. 13) - muito antes, portanto, da dissolução do "socialismo real" do Leste Europeu -, representa uma contribuição inestimável para reconstituição do pensamento marxiano.

A necessidade de restauração do marxismo era clara para Lukács nos anos de redação da Ontologia. No capítulo III, dedicado à análise da natureza ontológica do pensamento de Hegel, há uma espécie de declaração programática da obra onde esclarece que o objetivo do seu estudo era, antes de tudo, "reativar o contato com as grandes tradições do marxismo". Com esse propósito, elege um tema específico, a ontologia do ser social. E essa escolha se explica, de acordo com ele, porque, na atmosfera intelectual da época, saturada de "teorias tortuosamente elucubradas, vulgarmente niveladoras ou falsamente profundas", a reconstrução do marxismo exigiria uma

[...] ontologia fundada e fundante que encontre na realidade objetiva da natureza a base real do ser social e seja, ao mesmo tempo, capaz de apresentar o ser social em sua simultânea identidade e diferença com a ontologia da natureza (LUKÁCS, 1979a, p. 64).

A insistência na fundamentação ontológica, cumpre recordar, dá-se em uma época de ampla difusão e aceitação do expurgo da ontologia do campo da ciência, reivindicado pelo neopositivismo. Na crítica a esse expurgo, Lukács, de algum modo, parece antecipar a emergência de posições teóricas, como o pós-estruturalismo, o pósmoderno e o neopragmatismo, que, a partir do final dos anos 60 , a pretexto de exercitar a crítica ao cientificismo advogado pelo neopositivismo, adotam justamente a mesma postura, recusando toda referência à ontologia.

Diante dessas recusas, seria possível perguntar: por que a insistência? Por que ontologia? Naturalmente, toda a Ontologia do ser social é uma resposta fundamentada a essas perguntas. Para oferecer uma justificativa sintética e, talvez se possa dizer, incontestável em sua simplicidade, é suficiente repetir, com Bhaskar, que, uma vez que a "filosofia tem horror ao vácuo ontológico", toda posição teórica de recusa à ontologia é puramente nominal, pois está fundada sobre uma tácita ontologia pressuposta por sua epistemologia (BHASKAR, 1994, p. 48). Em outras palavras, toda reivindicação de conhecimento tem por pressuposto uma ideia, por geral que seja, da constituição do objeto do qual se reclama conhecimento. Em consequência, impugnar a ontologia significa adotar de forma acrítica concepções substantivas sobre o mundo. Por contraste, admitir o caráter incontornável da ontologia implica a necessidade de investigar as concepções que fundam nossas ideias e as práticas que elas facultam. Dito em outros termos, antes ter consciência da ontologia que informa nossas ações do que agir com base em noções irrefletidas sobre a realidade e que podem ser simplesmente falsas, pois são irrealizáveis as finalidades das práticas que se baseiam em noções falsas. Pode-se concluir, por conseguinte, que a ênfase na ontologia tem a verdade como corolário.

Thompson (1978, p. 138), em sua crítica ao ex-comunista Kolakowski, oferece uma ilustração interessante da questão ao assinalar que nós humanos, por possuirmos os "atributos de agentes morais ou de seres racionais", significamos compulsivamente. E o fazemos simplesmente porque nosso agir é teleológico, intencional. Pôr uma finalidade e agir em conformidade pressupõe, é evidente, uma figuração do mundo uma ontologia, cuja conformidade com a realidade é condição para a consecução da finalidade. Existe um incontornável nexo entre figuração de mundo, cuja norma básica é a "adequação representativa ou descritiva - ou verdade -, e prática humano-social, cuja norma básica é a realização ou satisfação dos desejos, necessidades ou propósitos humanos", de modo que, se há fundamentos reais para as crenças e, ipso facto, para as ações nelas baseadas, o erro sobre esses fundamentos reais ou a falha em capturar sua verdade resulta na impossibilidade de satisfação dos desejos e necessidades (BHASKAR, 1986, p. 206). Em suma, erro na teoria, fracasso na prática.

Tão mais relevante é a consideração explícita da ontologia subjacente às teorias porque, verdadeiras ou falsas,

[...] todas as representações ontológicas dos seres humanos, independentemente do grau de consciência em que isso ocorre, são amplamente influenciadas pela sociedade, e não vem ao caso se o componente dominante é o da vida cotidiana, o da fé religiosa etc. Essas representações cumprem um papel 
extremamente influente na práxis social dos seres humanos, condensando-se com frequência em um poder social real (LUKÁCS, 2004, p. 117).

Compreende-se, assim, o esforço de Lukács para a construção de uma ontologia no interior do marxismo - ou a importância que assume para ele a explicitação do fundamento ontológico do pensamento marxiano. Pois se as representações ontológicas são incontornáveis e centrais na práxis social dos sujeitos e, mesmo quando falsas, possuem um poder social real, resulta evidente que a crítica ontológica é um imperativo. Se as estruturas sociais geram e necessitam de representações ontológicas falsas por parte dos sujeitos, e por meio delas os sujeitos em sua práxis reproduzem essas estruturas, então somente uma crítica ontológica pode romper com tal círculo vicioso que necessariamente frustra os projetos de um mundo mais humano. Pode-se concluir, desse modo, que crítica genuína é crítica ontológica, e a restauração da dimensão crítica do pensamento marxiano pressupõe, como quer Lukács, a restituição de sua dimensão ontológica. Se Marx oferece outra figuração de mundo e, portanto, exercita uma crítica ontológica das formas de pensamento da sociedade capitalista (científicas e não científicas) e, na mesma medida, das estruturas e relações sociais que as produzem e requerem, a Ontologia de Lukács constitui uma contribuição ímpar para devolver ao pensamento marxiano a sua dimensão verdadeiramente crítica.

Por último, faltaria sublinhar que o artigo, ao acentuar a relevância da obra póstuma de Lukács, vai se concentrar em particular, mas não exclusivamente, no capítulo sobre o trabalho, onde o autor começa a delinear o ser social, capturando de maneira genial, no trabalho como categoria mediadora por excelência, a emergência de suas categorias específicas. Nesse particular, o artigo focaliza algumas dessas categorias que, inclusive em trabalhos dedicados à Ontologia do ser social, não costumam receber muito destaque ${ }^{2}$.

\section{Trabalho: categoria mediadora por excelência}

O trabalho, como atividade originária, põe na vida social uma progressiva diferenciação de complexos heterogêneos ${ }^{3}$. Com vistas a investigar a gênese do ser social, Lukács procura analisar os vínculos e as distinções entre o ser meramente orgânico (animal) e o ser social (humano). Nesse caso, ele esclarece também que se trata da passagem de um nível de ser a outro, ou seja, de um salto ontológico - uma mudança qualitativa e estrutural do ser. Ao contrário da continuidade normal do desenvolvimento, o salto consiste essencialmente em uma ruptura. A gênese do ser social pressupõe a superação qualitativa da vida orgânica, um processo de extrema lentidão, mas que não deixa de ser um salto.

Devido ao caráter histórico do ser social, não é possível investigar a sua gênese por meio de uma experiência que reproduza os momentos de transição entre o animal e o ser humano, isto é, está vedado o experimento de reconstrução das fases intermediárias desse processo. Ademais, o ser social, como estrutura superior, não deriva diretamente de estruturas naturais inferiores e menos desenvolvidas. Como se trata sempre de um salto, não seria possível inferir, seja por dedução ou por indução, a forma posterior das anteriores. Em outros termos, dada a impossibilidade de explorar a gênese do ser social através do estudo direto das formas orgânicas inferiores, Lukács realiza, a exemplo de Marx, o que se poderia denominar de análise retrodutiva ${ }^{4}$. Pode-se concordar com Tertulian (2009) que, no pensamento do último Lukács, há um método ontológico-genético que implica a admissão das diferentes formas de ser e, portanto, do caráter dinâmico da realidade, sua permanente diferenciação. Método que, por essa razão, reconhece e enfatiza a categoria da emergência. Sob essa perspectiva, por conseguinte, investigar uma forma de ser é investigar as categorias que determinam a sua especificidade, categorias por meio das quais ela emergiu das formas de ser precedentes e nas quais continua fundada.

Em conformidade com esse método, Lukács identifica no trabalho a categoria a partir da qual se deve investigar o complexo concreto da sociabilidade como forma de ser. O que significa dizer que, para ele, o trabalho é a categoria fundante do ser social e que, em germe, contém todas as outras determinações. Para esclarecer esse caráter fundante do trabalho, Lukács explicita outras três categorias decisivas - linguagem, sociabilidade e divisão do trabalho. Segundo ele, tanto a linguagem quanto a sociabilidade e a divisão do trabalho são categorias cuja existência e operação requerem que o ser social já esteja plenamente constituído, pressupondo o referido salto como já acontecido. Somente o trabalho é a categoria essencialmente intermediária, é o vínculo material e o objetivo entre ser humano e natureza, por esse motivo é a categoria fundante e mediadora por excelência, assinalando a passagem do ser meramente biológico ao ser social ${ }^{5}$. Lukács $(2004$, p. 58) argumenta que a essência do trabalho, "em primeiro lugar, [...] surge em meio à luta pela existência; em segundo lugar, que todas as suas etapas são produtos de sua atividade autônoma”. O caráter intermediário constitui a inter-relação entre ser humano (sociedade) e natureza (tanto inorgânica, quanto orgânica) para a produção de objetos úteis à vida (valores de uso). Com isso, Lukács (1979b) fixa, 
como Marx, o aspecto originário do trabalho, no sentido estrito do termo, como necessidade natural e eterna, independente das formações sociais. Talvez o mais importante seja sublinhar que é no trabalho que o ser social cria o seu mundo. As suas formas de objetividade - que, a partir do ser natural, tornam-se cada vez mais claramente sociais - resultam do trabalho e se desenvolvem à medida que a práxis social emerge e se torna cada vez mais explícita.

O complexo do trabalho é posto efetivamente em movimento pelo carecimento material cuja satisfação só se realiza como efeito de uma cadeia de mediações que, ontologicamente, existe em função dessa satisfação. Essa cadeia consiste nas relações entre o homem e a natureza que, progressivamente, são mediadas por categorias sociais mais complexas como resultado do impulso inerente ao próprio trabalho na superação da imediaticidade. O que equivale afirmar que a satisfação de necessidades através do trabalho é mediada e que todo produto do trabalho, quando terminado, tem para o homem que o utiliza uma nova imediaticidade, dessa vez não mais natural. Tais mediações transformam, de maneira contínua e simultânea, a natureza, os homens que nela atuam e as suas relações recíprocas. O caráter decisivo do trabalho como categoria fundante do ser social está inscrito nessa dinâmica. Na análise de Lukács (1979b, p. 87, 2004, p. 105, 142), a função ontologicamente fundante, primária, que cabe ao trabalho, não resulta de nenhuma hierarquia de valor, de uma valoração exclusiva da práxis laborativa. Trata-se, apenas, de um fato de caráter ontológico de uma determinada forma de ser. Neste sentido, Tertulian (2009, p. 403) observa que Lukács "pensador da pura existência terrestre" tem como objetivo demonstrar que no trabalho, como atividade originária, está enraizada a diferenciação progressiva da vida social em uma multiplicidade de complexos heterogêneos ${ }^{6}$. É a partir dessa visão ontológica básica que o método permite compreender o desenvolvimento genético das categorias superiores, mais mediadas e complexas. Em síntese:

No trabalho estão contidas in nuce todas as determinações que, como veremos, constituem a essência do novo dentro do ser social. O trabalho pode ser considerado, pois, como fenômeno originário [Urphänomen], como modelo do ser social; o esclarecimento destas determinações proporciona já, portanto, uma imagem tão clara acerca de suas características essenciais, que parece metodologicamente vantajoso começar com sua análise (LUKÁCS, 2004, p. 59).

Cabe aqui nomear e qualificar quais são essas determinações (categorias) que já estão pressupostas no trabalho e que são fundamentais para a compreensão da gênese e constituição do ser social. Para isso Lukács indaga: dado que o trabalho existe, quais as condições fundamentais que têm de estar presentes para que ele exista? Em resposta, deixa claro que para o trabalho existir é preciso que haja uma separação entre sujeito e objeto (mundo), e que o sujeito seja consciente de tal separação. Somente com esse distanciamento, o sujeito é capaz de pôr uma finalidade. $\mathrm{O}$ ato do pôr teleológico, além de exigir a consciência e a separação sujeito-objeto, requer que o sujeito tenha algum grau de conhecimento da natureza para permitir a concepção da finalidade e do modo adequado de manipular os meios naturais necessários para realização do fim idealmente posto. $\mathrm{O}$ conhecimento possibilitado pelo distanciamento pode ser considerado a realidade como possessão espiritual dos sujeitos. Lukács identifica nesse processo a gênese da ciência. Por último, concluindo a análise, ele assinala que o trabalho tem por pressuposto que o sujeito que põe e realiza a finalidade decidiu diante de um rol de alternativas, baseado em uma determinada valoração, qual caminho objetivamente seguir para realizar o fim posto. Se é possível escolher entre diversas alternativas, pode-se reconhecer que o trabalho consiste em um ato de liberdade. Desta forma, finalidade, separação sujeito-objeto, consciência, conhecimento, alternativa, valor e liberdade, são categorias inerentes ao trabalho e ao ser social.

O trabalho é, pois, o momento predominante no salto

... restaurar a crítica ontológica do pensamento marxiano exige reconhecer o caráter fundante (e ineliminável) da categoria trabalho na gênese $\mathrm{e}$ complexificação do ser social, e, simultaneamente, impõe a necessidade de crítica à centralidade do trabalho, o que nem sempre ocorre no interior da tradição marxista. ontológico entre o mundo natural e o estabelecimento da vida especificamente humana. Ele se apresenta como meio da autocriação do ser humano como ser humano: 
Enquanto ser biológico, o ser humano é um produto da evolução natural. Com sua autorrealização, que, naturalmente, também nele mesmo pode significar um retrocesso dos limites naturais, mas nunca o desaparecimento, a plena superação desses limites, o ser humano ingressa num novo ser e por ele mesmo fundado: o ser social (LUKÁCS, 2004, p. 102).

Como se sabe, Marx sublinha que o ser humano tem a capacidade de projetar previamente aquilo que depois vai produzir. Na formulação marxiana, a categoria do trabalho constitui a realização de um pôr teleológico que dá origem a uma nova objetividade (produtos do trabalho), o que implica sua tendência a um continuado desenvolvimento e evidencia o caráter não epifenomênico da consciência. Por contraste, a estruturação existente nas chamadas sociedades animais, por exemplo, das abelhas e das formigas, consiste em uma regulação biológica das ações e, por isso, rigidamente fixada sem possibilidade de desenvolvimento. Em consequência, ali o papel da consciência, quando ela existe, é meramente epifenomênico, ou seja, não vai além do serviço imediato à existência biológica e à reprodução (LUKÁCS, 2004, p. 80).

Se o fundamental no trabalho, portanto, é o pôr teleológico, esse é o momento adequado para qualificar com mais precisão as duas categorias heterogêneas nele envolvidas: (a) causalidade, característica dos processos naturais (inorgânicos e orgânicos) que operam por si mesmos; e (b) teleologia, que é uma categoria posta e implica uma consciência que põe e realiza uma finalidade. Teleologia diz respeito a processos sociais, do ser social que, diferentemente dos processos puramente causais, não estão no âmbito da necessidade natural, ocorrem por força de uma decisão da consciência. Daí Lukács afirmar que o trabalho converte puras causalidades (que são dadas e naturais) em causalidades postas.

$\mathrm{O}$ autor, para esclarecer o nexo entre causalidade e teleologia inerente ao trabalho, recorre às análises de Aristóteles e Hartmann. Em Aristóteles, o trabalho tem dois componentes: o pensar (noésis), onde um fim é posto e buscam-se os meios; e o produzir (poiésis), onde a finalidade se realiza. Hartmann, por sua vez, faz importante distinção no pensar entre a posição dos fins e a investigação dos meios. Lukács considera tal distinção da máxima relevância porque localiza e revela a inseparável ligação das categorias causalidade e teleologia, que em si mesmas são heterogêneas, e que são homogeneizadas no processo de investigação dos meios para realizar um fim. A busca dos meios tem, portanto, a dupla função de evidenciar o sistema causal dos objetos e dos processos (aquilo que governa os objetos e suas relações) e descobrir neles novas possíveis conexões que, quando postas em movimento, tornam efetivável o fim posto. Em decorrência, Lukács afirma que o produto do trabalho é em si uma homogeneidade, é superação de heterogeneidades. A "lógica" da natureza, o ser das coisas existentes na natureza não é nem está de nenhuma forma adequado e/ou direcionado para o atendimento de necessidades humanas. Por isso, a natureza é heterogênea em relação às necessidades do ser humano e às finalidades por ele postas. Somente o trabalho, ao organizar as propriedades da natureza de uma forma nova e diferente da original, pode superar a mencionada heterogeneidade e fazer nascer um produto que atenda às necessidades humanas. Assim, "natureza e trabalho, meio e fim, produzem, pois, dessa maneira, algo em si homogêneo: o processo de trabalho e, ao fim, o produto do trabalho" (LUKÁCS, 2004, p. 71).

\section{Separação sujeito-objeto, conhecimento e gênese da ciência}

Para que exista trabalho e, assim, finalidades sejam postas, é necessário que haja relação sujeito-objeto. Tal relação pressupõe um distanciamento da realidade que é intrínseco à posição teleológica e envolve, ao mesmo tempo, a apreensão conceitual do objeto. Nesse sentido, diz Lukács (2004, p. 115), "o sujeito só se converte em sujeito pelo fato de consumar uma transformação semelhante de sua atitude frente aos objetos do mundo exterior". Logo, o trabalho pressupõe o sujeito que se relaciona com o meio e dessa relação surge como fato necessário o distanciamento ou separação sujeito-objeto. A relação sujeito-objeto e a separação daí resultante são dois momentos que implicam a emergência da compreensão da realidade exterior na forma de conceito e a expressão de tal realidade por meio da linguagem. Assim, fica configurado, a partir das condições ontológicas da gênese do trabalho, o fenômeno exclusivamente humano de captura da realidade como possessão espiritual. Esse fenômeno está na raiz do processo de conhecimento, cujo aprimoramento continuado conduz à gênese da ciência. Por essa razão, tanto o conhecimento nos seus estágios mais simples quanto a própria ciência têm seus fundamentos ontológicos no trabalho:

A posição do fim se origina numa necessidade humano-social; mas, a fim de que chegue a uma posição autêntica do fim, a investigação dos meios (isto é, o conhecimento da natureza) deve ter alcançado um determinado nível, coerente com esses meios; se esse nível ainda não foi alcançado, a posição do fim perma- 
nece como projeto meramente utópico, uma espécie de sonho [...]. O ponto, pois, no qual o trabalho se relaciona, desde o ponto de vista da ontologia do ser social, com o surgimento do pensamento científico e sua evolução, é precisamente o âmbito por nós denominado investigação dos meios (LUKÁCS, 2004, p. 73).

Evidentemente, o trabalho não pode se realizar sem o mínimo de conhecimento da natureza. Portanto é importante esclarecer a ligação do trabalho com o pensamento científico e o seu desenvolvimento. O trabalho é condicionado pelo nível de conhecimento já adquirido e fixado socialmente. Ao mesmo tempo, a própria finalidade determina o critério da verdade, ou seja, "em cada processo de trabalho concreto e individual, o fim domina e regula os meios" (LUKÁCS, 2004, p. 73). Contudo, Lukács observa que, levando em conta a evolução histórica dos processos de trabalho em sua continuidade, esta relação hierárquica é invertida, de modo que os meios adquirem progressivamente maior importância que os fins. As finalidades, por serem direcionadas à satisfação direta e imediata de necessidades, passam e são esquecidas, enquanto os meios, os instrumentos conservam-se. Como a pesquisa da natureza está concentrada na preparação dos meios, são estes a garantia social da conservação dos resultados do trabalho, que são fixados e possibilitam um desenvolvimento continuado. Daí Lukács sugerir que a gênese da ciência está ligada à investigação dos meios, e que esta, ao se constituir como uma esfera autônoma específica, tem a busca da verdade como finalidade, distanciando-se em grande medida das finalidades particulares dos processos de trabalho imediatos.

\section{Categoria da alternativa e a gênese ontológica do valor e da liberdade}

Viu-se que Lukács realça o conteúdo determinante de categorias que têm a gênese, de um modo ontologicamente necessário, no trabalho, e que, por isso, fazem dele o modelo da práxis social em geral. Das categorias que merecem destaque especial no capítulo do trabalho já foram consideradas: finalidade, consciência, separação sujeito-objeto e ciência. Faltaria tematizar alternativa, liberdade e valor. Na vida humana emergem tipos de comportamento que se tornam decisivos para o ser homem do homem, ou para o ser humano transformar-se em ser humano. Nesta perspectiva, Tertulian (2009, p. 395) ressalta que o método ontológicogenético lukácsiano permite indicar a gênese da transcendência do ser humano a partir do distanciamento da natureza presente já nos atos mais elementares do trabalho, implicando, entre outros aspectos, o controle dos afetos e a emergência da autorrealização de si. Trata-se daquilo que Marx chamou de "recuo das barreiras naturais" - que, se bem retrocedem de maneira contínua, nunca desaparecem por completo - e expressa o desenvolvimento de categorias mais complexas e mais mediadas que se interpõem entre a necessidade e a sua satisfação (LUKÁCS, 1979b, p. 18-20, 53-54, 2004, p. 56-57).

O trabalho provoca modificações na natureza do próprio sujeito que o realiza, por isso, para Lukács, o ponto central do processo de transformação interna do ser humano consiste no domínio consciente de si mesmo, do seu próprio corpo, dos instintos e afetos. O domínio consciente sobre os afetos é o domínio do consciente sobre o puramente instintivo, representando também um momento do "salto", da saída do homem da existência puramente animal. O autodomínio é um pressuposto necessário para realizar no trabalho os próprios fins autonomamente postos. Esse controle retrata uma atitude qualitativamente diferente e heterogênea em relação à condição animal e cuja exigência é posta por todo tipo de trabalho, inclusive o mais primitivo. Pode-se reafirmar, também por isso, que a consciência humana não é um epifenômeno biológico, mas um momento essencial ativo na gênese do ser social.

$\mathrm{Na}$ dinâmica entre necessidade humana e satisfação, interpõe-se o trabalho, que em si tem como essência a posição de finalidade. Para que a finalidade se realize, a consciência tem de tomar decisões que incidem sobre o ser-em-si de tudo o que se relaciona com o trabalho, sendo preciso reconhecer determinadas propriedades do objeto e do instrumento escolhidos, através da observação e da experiência, que os tornam adequados ou inadequados para a finalidade planejada. Tais decisões remetem à categoria da alternativa, que, para Lukács, constitui a nova categoria decisiva do ser social e que em si contém a gênese ontológica da liberdade e do valor.

A alternativa efetiva a passagem da possibilidade à realidade. No ato da alternativa está presente o momento da decisão, da escolha. Todavia, a alternativa não é um ato único de decisão, a práxis humano-social sempre implica uma cadeia ininterrupta de alternativas sempre novas e a consciência humana é o lugar e o órgão da decisão. Por isso, a alternativa, sublinha Lukács, possui um insuprimível caráter cognitivo. Ao se interpor como mediação entre necessidade e satisfação imediata, o trabalho denota uma vitória do comportamento consciente sobre a mera espontaneidade do biologicamente instintivo. Esse fato aparece de maneira mais clara quando, no trabalho, a mediação compreende uma cadeia de alternativas, sendo preciso, portanto, descartar todo o simplesmente instintivo, ou emotivo, que poderia perturbar o reflexo da 
realidade objetiva. Aqui, nota-se outra vez o caráter não epifenomênico da consciência humana.

A alternativa é a categoria mediadora através da qual o reflexo da realidade se torna veículo do pôr uma existência, uma realidade, de maneira que, desse ser existente, surge uma forma de objetividade radicalmente nova (LUKÁCS, 2004, p. 91). Nos termos do autor:

[...] quando os resultados do reflexo não existente se cristalizam numa práxis estruturada em termos de alternativa, a partir daquilo que existe somente de maneira natural, pode surgir algo existente no marco do ser social - por exemplo, uma faca ou um machado -, isto é, surge uma forma de objetividade desse ser existente total e radicalmente nova. Pois, a pedra, na sua existência e em seu ser-em-si natural, nada tem a ver com a faca ou o machado (LUKÁCS, 2004, p. 89).

Da análise da alternativa se desdobra imediatamente a problemática do valor. As alternativas concretas do trabalho implicam uma escolha entre certo e errado na determinação do fim, na definição dos meios e na execução. Lukács observa que na práxis econômica as alternativas não são resultado de valores subjetivos individuais, mas é a subjetividade no interior do ser social, em cada fase do desenvolvimento histórico, que estabelece se são certas ou erradas as posições alternativas orientadas para o valor. Os valores se conservam e se renovam ininterruptamente no conjunto do processo social, sua mudança e permanência são produto do desenvolvimento social e estão ancorados nas necessidades sociais de cada época. Logo, "a objetividade dos valores se baseia, pois, em que eles são componentes motores e movidos da inteira evolução social" (LUKÁCS, 2004, p. 151).

No trabalho, a gênese ontológica do valor - cuja presença efetiva se circunscreve ao ser social - deriva do fato de que a alternativa opera como elemento ativo do ser social na determinação do que é útil ou inútil para a satisfação das necessidades. O valor confere ao trabalho uma objetividade social e fornece o critério que estabelece se as alternativas presentes na posição teleológica e em sua efetivação são adequadas, válidas, e corretas (LUKÁCS, 2004, p. 136). Os valores são produto do desenvolvimento social, funcionam como determinações de todo tipo de práxis e constituem o pressuposto objetivo para o dever-ser que aciona o agir humano em resposta aos carecimentos, projetos, e desejos. Lukács (1978) afirma que o essencial ao trabalho é que todo movimento é submetido a um dever-ser; tanto os movimentos quanto os homens que o realizam devem ser dirigidos por finalidades determinadas previamente.

Com a satisfação da necessidade, a posição teleológica pode ter a sua existência objetiva e válida demonstrada na sua relação de "se... então" com uma abstração orientada para a legalidade sempre concreta, na medida em que um objeto produzido só tem valor quando serve corretamente e da maneira mais adequada à satisfação da necessidade (LUKÁCS, 2004, p. 136). O caráter relativo e condicionado da necessidade é acentuado por Lukács quando faz referência a uma necessidade do tipo "se... então", em que ela aparece em função das distintas determinações do real, em oposição a um caráter todo poderoso e transcendente que elevaria a necessidade a uma esfera abstrato-absoluta. Cabe, aqui, fazer referência ao questionamento de Lukács à interpretação de Engels, que, à diferença do pensamento autenticamente ontológico de Marx, parecia-lhe impregnada pelo logicismo hegeliano ${ }^{7}$. Para Lukács, disso resulta, na análise de Engels, o crédito excessivo à força coercitiva da necessidade e a subestimação do peso das contingências. É no contexto dessa crítica que Tertulian (2009) observa que Lukács formulou o conceito "se... então" para fazer valer a presença da possibilidade e da contingência nos encadeamentos causais com o objetivo de combater a ideia do caráter unívoco do desenvolvimento histórico, pois ocultar o peso das categorias da possibilidade e da contingência, assim como, a heterogeneidade dos componentes do processo histórico "acabava por sacrificar a diferença do desenvolvimento dos distintos complexos a uma visão retilínea e monolítica" (TERTULIAN, 2007, p. 227). Assim, em contraposição a uma realidade acabada ou predeterminada, conforme afirma Lukács (2004, p. 176), na compreensão do trabalho numa perspectiva ontológica, o momento da transformação do sujeito que trabalha "é um despertar sistemático de possibilidades" e um desenvolvimento contínuo que permite "que possibilidades sempre novas madurem no ser humano até se converter em realidades".

Conforme explicitado anteriormente, a gênese ontológica da liberdade deriva da alternativa e tem sua constituição ontológica determinada pelo caráter fundamental do trabalho para a humanização do ser humano. A posição de um fim que põe algo novo, como resultado de ações decididas e executadas conscientemente, é identificada por Lukács (2004, p. 169) como um ato emergente de liberdade:

[...] quanto maior for o conhecimento adequado das cadeias causais que operam no caso em questão, tanto mais adequadamente poderão ser transformadas em cadeias causais postas, tanto maior será o domínio que o sujeito exerce sobre elas, ou seja, a liberdade que aqui pode alcançar. 
O trabalho revela o ponto de partida genético da liberdade, e representa outra questão vital na gênese e no desenvolvimento do ser social. $\mathrm{O}$ fenômeno da liberdade, completamente estranho à natureza, aparece no momento em que a consciência decide, em termos alternativos, qual finalidade quer pôr e de que maneira quer transformar séries causais naturais em séries causais postas como meios de sua realização (LUKÁCS, 2004, p. 166).

$\mathrm{O}$ autor alerta para o fato de que na realização de um fim está contida a simultaneidade de determinismo e liberdade. A posição de um fim é um ato de liberdade, pois os modos e meios de satisfazer uma necessidade são resultados de ações decididas e executadas conscientemente, e não produtos de cadeias causais espontaneamente biológicas. Entretanto, a liberdade (da decisão alternativa) jamais está isenta de determinismo, pois a liberdade não é abstrata, é característica do ser humano que vive na sociedade e age socialmente, sendo, portanto, condicionada social e historicamente.

\section{À guisa de conclusão}

Sob essa ótica, o único caminho para chegar à liberdade humana real é, de fato, o caminho do autocontrole, a passagem do determinismo natural dos instintos ao autodomínio consciente. Como já se observou, o autocontrole é um ato de liberdade contra a espontaneidade meramente natural. O fundamento da liberdade para a vida do ser humano consiste na conquista sobre si mesmo e sobre a própria natureza, originalmente apenas orgânica. É só com a emergência da liberdade, do ponto de vista ontológico genético, que sucede a

[...] superação da mudez meramente orgânica do gênero, sua continuação no gênero articulado, em desenvolvimento, do ser humano que se forma enquanto ente social, é - considerada desde um ponto de vista ontológico-genético - o mesmo ato que o do surgimento da liberdade (LUKÁCS, 2004, p. 187).

De acordo com Lukács, a plena realização da liberdade exige o controle do trabalho por parte da humanidade. O que equivale dizer que o autor, baseado em Marx, sustenta uma compreensão ontológica do trabalho como um ato de liberdade e, ao mesmo tempo, explicita uma crítica ontológica do trabalho na sociedade capitalista. A centralidade que o trabalho assume nessa sociedade, em lugar de representar o controle do trabalho por parte da humanidade, o que seria a efetivação dessa liberdade plena, significa antes a sua dominação abstrata pela dinâmica de seu produto, sua autoescravização:

Só quando o trabalho for efetiva e completamente dominado pela humanidade e, portanto, só quando ele tiver em si a possibilidade de ser 'não apenas meio de vida', mas 'o primeiro carecimento da vida', só quando a humanidade tiver superado qualquer caráter coercitivo em sua própria autoprodução, só então terá sido aberto o caminho social da atividade humana como fim autônomo (LUKÁCS, 1978, p. 16).

Pode-se concluir, então, que restaurar a crítica ontológica do pensamento marxiano exige reconhecer o caráter fundante (e ineliminável) da categoria trabalho na gênese e complexificação do ser social, impondo, simultaneamente, a necessidade de crítica à centralidade do trabalho, o que nem sempre ocorre no interior da tradição marxista.

\section{Referências}

BHASKAR, R. Scientific Realism and Human Emancipation. London: Verso, 1986. . Plato etc.: The Problems of Philosophy and their Resolution. New York: Verso, 1994.

LUKÁCS, G. As bases ontológicas do pensamento e da atividade do homem. Temas de Ciências Humanas, tradução de Carlos Nelson Coutinho, São Paulo: Livraria Editora Ciências Humanas, n. 4, p. 1-18, 1978.

. A falsa e a verdadeira ontologia de Hegel. Tradução de Carlos Nelson Coutinho. São Paulo: Lech, 1979a.

. Ontologia do ser social. Os princípios ontológicos fundamentais de Marx. Tradução de Carlos Nelson Coutinho. São Paulo:

Livraria Ciências Humanas, 1979b.

. Zur Ontologie des gesellschaftlichen Seins. 1. Halbband, I-1, Neopositivismus. Darmstadt: Luchterhand, 1984.

.Zur Ontologie des gesellschaftlichen Seins. 2. Halbband, 2-1, Die Arbeit. Darmstadt: Luchterhand, 1986.

. Pensamento vivido: autobiografia em diálogo. Entrevista a István Eörsi e Erzsébet Vezér. Tradução de C. A. Franco. Viçosa: Ad

Hominem, 1999.

. Ontología del ser social: el trabajo. Traducción de Antonino Infranca e Miguel Vedda. Buenos Aires: Herramienta, 2004.

TERTUliAN, N. O pensamento do último Lukács. Revista Outubro, São Paulo, n. 16, p. 219-248, 2007. 
2009.

Sobre o método ontológico-genético em Filosofia. Revista Perspectiva, Florianópolis: Edufsc, v. 27, n. 2, p. 375-408, jul./dez.

THOMPSON, E. P. An Open Letter to Leszek Kolakowski. In: The Poverty of Theory and Other Essays. New York: Monthly

Review Press, 1978.

\section{Notas}

1 Concepção idêntica aparece na seguinte formulação de Lukács: “o ponto de vista ontológico é inevitável; [ . . . ] e essa inevitabilidade não se limita à filosofia enquanto tal, mas termina por surgir espontaneamente em toda consideração científica” (LUKÁCS, 1979a, p. 92).

2 Sobre o tema ontologia do ser social, observa-se que há uma ampla utilização na literatura corrente do Serviço Social de duas publicações de Lukács. A primeira é o texto redigido para uma conferência intitulado As bases ontológicas do pensamento e da atividade do homem (Lukács, 1978), sendo reconhecido pelo mérito de fornecer uma síntese da investigação ontológica do autor. A segunda é a seção 1 (Questões metodológicas preliminares) do capítulo IV (primeira parte), Os princípios ontológicos fundamentais de Marx, da obra Ontologia do ser social (LUKÁCS, 1979b, p. 11-34). No presente artigo, procura-se discutir o tema baseado principalmente no capítulo I(segunda parte), O trabalho (Lukács, 2004). Em alguns casos, a tradução emespanhol foi cotejada como original emalemão(Lukács, 1986).

3 "Se ele [Lukács] identifica no trabalho a célula geratriz (o Urphänomen) da vida social, analisando a maneira pela qual as objetivações mais complexas e mais sofisticadas retomam o modelo da relação sujeito-objeto, forjada pelo trabalho, isso não significa reduzir a vida social ao 'paradigma do trabalho' [...]. Seu objetivo era demonstrar como a diferenciação progressiva da vida social em uma multiplicidade de complexos heterogêneos se enraíza nesta atividade originária que é o trabalho" (TERTULIAN, 2009, p. 380-381).

4 Ver Bhaskar (1986, cap. 1).

5 Lukács (1979b, p. 40) explicita que atribuir prioridade ontológica à determinada categoria em relação a outra significa que a primeira pode existir sem a segunda, mas o contrário é ontologicamente impossível. Pode existir ser sem consciência, mas não pode existir consciência sem ser a prioridade ontológica do trabalho, em relação a outras formas de atividade, é assim sintetizada: "o trabalho é antes de mais nada, em termos genéticos, o ponto de partida da humanização do homem, do refinamento de suas faculdades, processo do qual não se deve esquecer o domínio sobre si mesmo. Além do mais, o trabalho se apresenta, por um longo tempo, como o único âmbito desse desenvolvimento; todas as demais formas de atividade do homem, ligadas aos diversos valores, só se podem apresentar como autônomas depois que o trabalho atinge um nível relativamente elevado" (LUKÁCS, 1979b, p. 87).

6 Tertulian (2009, p. 387), na tentativa de elucidar a posição de Lukács no cenário filosófico contemporâneo, observa que a prioridade ontológica do trabalho não significa a ocultação das outras formas de intersubjetividade, como a política, o direito, a moral e a ética.

7 Sobre este aspecto ver: Lukács (1979b, p. 114-125, 2004, p. 171-174) e Tertulian (1990, p. 2-8).

\section{Mario Duayer}

mddier@gmail.com

Pós-Doutorado em Economia na Duke University

Doutorado em Desenvolvimento e Transferência de Tecnologia pela Universidade de Manchester (UK)

Professor Visitante do Programa de Pós-Graduação em Serviço Social da Universidade do Estado do Rio de Janeiro (UERJ)

\section{María Fernanda Escurra}

mfescurra@gmail.com.br

Doutoranda do Programa de Pós-Graduação em Serviço Social da UERJ

\section{Andrea Vieira Siqueira}

andrea.natan@hotmail.com

Professora Assistente do Departamento de Ciências Humanas da Faculdade Estadual de Filosofia, Ciências e Letras de Paranaguá (Fafipar/UEPR)

Doutoranda do Programa de Pós-Graduação em Serviço Social da UERJ

\section{UERJ - Programa de Pós-Graduação em Serviço Social}

Rua São Francisco Xavier, 524, Bloco D, sala 9002

Maracanã

Rio de Janeiro - Rio de Janeiro - Brasil

CEP: 20550-013 